\title{
Colombia y el Acuerdo de Paz con las FARC-EP: entre la paz territorial que no llega y la violencia que no cesa
}

Colombia and the Peace Agreement with the FARC-EP: Between the territorial peace that does not come and the violence that does not cease

\author{
JERÓNIMO RÍOS \\ Universidad Complutense de Madrid \\ JULIO C. GONZÁLEZ \\ Universidad Militar Nueva Granada
}

\section{Cómo citar/Citation}

Ríos, J. y González, J. C. (2021). Colombia y el Acuerdo de Paz con las FARC-EP: entre la paz territorial que no llega y la violencia que no cesa. Revista Española de Ciencia Política, 55, 63-91. Doi: https://doi.org/10.21308/recp.55.03

\section{Resumen}

Este artículo tiene como principal propósito analizar la dimensión territorial de la construcción de paz prevista en el Acuerdo de Paz con las FARC-EP. Tras casi cuatro años desde su firma, la situación de violencia dirigida contra los desmovilizados de la guerrilla y líderes sociales exhibe las dificultades del Estado colombiano para transformar las dinámicas territoriales del conflicto. Como se mostrará, esta violencia, además, tiene un marcado componente periférico al concentrarse mayormente en los departamentos colombianos del nororiente, de la región Pacífico y del sur y el suroccidente. Allí concurren, muy particularmente, la presencia de las mayores estructuras criminales, la casi totalidad de la superficie cocalera y dinámicas de violencia estructural y debilidad institucional notables. Todos estos factores serán abordados, mayormente, a través de los datos ofrecidos por fuentes gubernamentales y complementados por herramientas de análisis elaboradas por los autores.

Palabras clave: Acuerdo de Paz, Colombia, conflicto armado, paz territorial, violencia.

\section{Abstract}

The purpose of is article is to analyze the territorial dimension of peacebuilding included in the Peace Agreement with the FARC-EP. After almost four years since its signing, the situation of 
violence against former guerrilla combatants and social leaders shows the difficulties of the Colombian State to transform the territorial dynamics of the conflict. As it will be shown, this violence, in addition, has a notable peripheral component; for it mainly happens in the Colombian departments of the Northeast, the Pacific region and the South and the Southwest. Specifically, there come together the largest presence of criminal structures, almost all the coca-growing area and pressing dynamics of structural violence and institutional weakness. All these factors will be mainly addressed through the data offered by government sources and complemented by analysis tools prepared by the authors.

Keywords: Peace Agreement, Colombia, armed conflict, territorial peace, violence.

\section{INTRODUCCIÓN}

El Acuerdo de Paz suscrito entre el Gobierno de Colombia y la guerrilla de las Fuerzas Armadas Revolucionarias de Colombia-Ejército del Pueblo (FARC-EP) supuso un hito destacable en la historia del conflicto armado colombiano. Este se remontaba formalmente a 1964, y a expensas de saber cómo se resolvería la negociación con la guerrilla del Ejército de Liberación Nacional (ELN), el Acuerdo cerraba más de medio siglo de confrontación armada en el último país del continente con insurgencias producidas tras la revolución cubana y en el marco de la Guerra Fría.

El Instituto Kroc de la Universidad de Notre Dame (2017), que ha sistematizado 34 acuerdos de paz que involucraron a más de medio centenar de grupos armados y que hace el seguimiento oficial al suscrito con las FARC-EP, destacó que el acuerdo colombiano era, de todos ellos, el más ambicioso y completo. Entre algunos de sus elementos más destacables cabe reseñar lo que se definió como "paz territorial» (Cairo et al., 2018); es decir, la necesidad de identificar, analizar e intervenir en las variables estructurales, culturales y simbólicas que mayormente se habían desarrollado en la Colombia olvidada, testigo del segundo conflicto más virulento de la historia de la región tras Guatemala (Centro Nacional de Memoria Histórica, 2013).

Transcurridos cuatro años desde la firma del Acuerdo de Paz en el Teatro Colón de Bogotá, el 24 de noviembre de 2016, la pregunta de investigación de la que parte este trabajo es la siguiente: ¿cuál ha sido el alcance y significado de esta paz territorial en Colombia? Es decir, tras estos primeros años de implementación del Acuerdo, ¿se aprecian cambios significativos en las dinámicas de la violencia asociadas al conflicto armado interno? Así, el objetivo general de esta aportación es analizar si se ha avanzado verdaderamente en la transformación de los condicionantes de la violencia en aquellos territorios que otrora resultaron más afectados por el conflicto con las FARC-EP. La hipótesis de partida invita al pesimismo, pues se propone que, más allá de las posibilidades que ofrece el Acuerdo, la realidad de la geografía de la violencia, lejos de haber cambiado, más bien pareciera haberse intensificado.

La violencia directa, traducida en homicidios directamente asociados al conflicto armado, como pueden ser los causados a excombatientes de las FARC-EP o a líderes 
sociales comprometidos con el Acuerdo de Paz, mantiene unos niveles de intensidad significativos (Ríos et al., 2020). Lo anterior, producto de la concurrencia de factores que, a modo de variables intervinientes, dificultan cualquier atisbo de paz estable y duradera en estos enclaves. La violencia estructural irresoluta, yuxtapuesta a una condición periférica, hostil y fronteriza, en donde se condensan los mayores niveles de cultivos cocaleros, y la mayor concurrencia de grupos armados y estructuras criminales dificultan el componente de paz territorial al que tanta importancia confiere el Acuerdo de Paz.

Este trabajo se organiza en cinco partes. En primer lugar, se identifican los elementos teóricos que permiten entender una geografía de la violencia como la colombiana, y que han sido ampliamente abordados desde la ciencia política en general y la geografía política en particular. En segundo lugar, se establece el marco analítico de referencia, acompañado de la identificación de las fuentes de información y el manejo de datos y estadísticas directamente asociados a la violencia tras el Acuerdo de Paz. Posteriormente, se describen los principales componentes que sustantivan la paz territorial en aquel. En cuarto y quinto lugar, se propone un doble análisis en el que se abordan los elementos geográficos, estructurales y criminales que han lastrado la construcción de paz en Colombia desde una perspectiva territorial. Finalmente, las conclusiones, además de servir de corolario al trabajo, presentan posibles líneas de investigación futura con las que dar continuidad a un objeto de estudio tan prolijo como vigente.

\section{MARCO TEÓRICO}

Durante los últimos años, la geografía política como subdisciplina de la ciencia política ha centrado su atención en entender la violencia desde una mirada estrictamente territorial (Ríos, 2017). Es posible encontrar análisis espaciales de la violencia y la (in)seguridad, ya sea atendiendo a diferentes tipos de población (Raleigh y Hegre, 2009), condiciones estructurales como la pobreza (Hegre et al., 2009), dimensiones fronterizas (Buhaug y Rød, 2006), de acuerdo con la presencia de recursos saqueables como el gas o el petróleo (Basedau y Pierskalla, 2013) o a partir del vínculo entre violencia y pluralidad étnica (McDoom, 2014).

Una premisa de partida es que las condiciones demográficas, sociales o culturales de un determinado territorio influyen y retroalimentan los contextos espaciales en donde tiene lugar la violencia. Esta solo es inteligible cuando se entiende como producto de la interacción entre una población y un lugar. Es decir, la relación del individuo —o grupo social — con el ambiente que le rodea desemboca en la construcción de un contexto espacial en el que cobran significado múltiples interacciones en forma de cotidianidad (Agnew, 1987), construcciones sociales (Pattie y Johnston, 2000) e imbricación multiescalar (Taylor y Flint, 2011).

Lo anterior ayuda a comprender por qué ciertos lugares de Colombia, y no otros, pueden albergar mayor o menor violencia (Zukerman, 2012). Al respecto, Linke y O'Loughlin (2015) entienden la violencia a partir de factores como el orgullo nacional, 
el capital social, el separatismo o su mayor exposición frente al enemigo. Todas ellas son variables particulares de la localidad e igualmente están presentes en trabajos como el de Schutte y Donnay (2014).

Especial atención cobran los escenarios vulgarmente denominados como periféricos y que, como sucede con algunos de los enclaves colombianos, resultan de muy difícil accesibilidad y guardan una mayor distancia con los centros económicos y políticos del país, como proponen Horowitz (1985), Bracanti (2006) o Schutte (2015). Esta hipótesis es planteada por Forø y Bahaug (2015), quienes afirman que elementos como la distancia con la ciudad, la disponibilidad de corredores y refugios selváticos o montańosos y la brecha sociocultural con los centros políticos y económicos del país (inaccessibility) favorecen la aparición de insurgencias.

Así, producto de una marcada fractura regional, concurrente con una ausencia de infraestructura y la presencia de imaginarios distanciados en clave de unidad nacional, los enclaves periféricos reúnen condiciones idóneas para la preservación de la violencia (Buhaug y Rød, 2006; Saleyhan, 2009). Una realidad frente a la que cabe añadir otros elementos como la existencia de fronteras inestables y permeables (O'Loughlin, 2012) o el asentamiento de comunidades étnicas trasnacionales en disputa con la impronta (mono)nacional del Estado (Cederman et al., 2013). En cualquier caso, cabría presumir que, a mayor distancia respecto de los centros decisorios de un Estado y mayor fractura territorial, mayores son las posibilidades de insurgencias cuando, entre medias, además, transcurren conflictos étnico-culturales o la presencia de recursos que ofrecen ingresos económicos a los posibles actores armados (Snyder, 2006).

Un acuerdo de paz como el suscrito en La Habana, entre otras cuestiones debe tener en consideración aspectos como los señalados para asentar las bases de un proceso de paz estable y duradera. Trayendo a colación el trabajo clásico de Galtung (1969), la paz, lejos de ser la ausencia de violencia, debe entenderse como la transformación y superación de los condicionantes estructurales y simbólicos que sostienen la misma, algo que está presente en la literatura especializada sobre resolución de conflictos y construcción de paz. Al respecto, Collier (2009) enfatiza la necesidad de desplegar recursos económicos que mitiguen los factores que espolean la violencia, toda vez que Nussio (2018) destaca lo imprescindible de llevar lo anterior al plano personal de los excombatientes que se desmovilizan. También es importante la construcción de ciertas capacidades institucionales (Hendrix, 2010), la generación de oportunidades socioeconómicas (Hill et al., 2008), el desarrollo de mecanismos redistributivos eficientes (Collier, 1994) y la actuación sobre los recursos ilícitos que financian un conflicto armado (Mashike, 2007). Esto, entre otros muchos factores a tener en cuenta a la hora de asumir todo proceso de construcción de paz.

\section{MARCO ANALÍTICO Y FUENTES DE INFORMACIÓN}

Este trabajo se caracteriza por ser un ejercicio exploratorio y analítico que busca evaluar el componente territorial del Acuerdo de Paz suscrito con las FARC-EP. La 
hipótesis de partida es que cuatro años después de su firma no se aprecian elementos que permitan vislumbrar un proceso efectivo de paz territorial, tal y como abogaba el Acuerdo. Así, y como en el siguiente epígrafe se podrá observar, en buena parte del articulado y en los cinco puntos negociados (además de la verificación e implementación) resulta posible encontrar un marcado acento en favor del territorio y de aquellos municipios que durante décadas conformaron las regiones más golpeadas por la violencia, si bien en ningún momento aparece como tal la expresión «paz territorial». (Cairo y Ríos, 2019). Es decir, la participación política, la construcción de capacidades socioeconómicas o la orientación de la erradicación de los cultivos cocaleros se plantean desde los territorios, con las comunidades de base, reconstruyendo el tejido social y la articulación de la ciudadanía con las instituciones. Tal vez resulte ilustrativa la manera en cómo se define la «paz territorial» por su principal valedor, quien fuera Alto Comisionado de Paz durante el Gobierno de Juan Manuel Santos, Sergio Jaramillo:

Lo que me interesa resaltar es que tenemos que aprovechar el momento de la paz para alinear los incentivos y desarrollar las instituciones en el territorio que con el tiempo van a hacer valer los derechos de todos por igual. [...] Para avanzar en esa dirección, hay que complementar el enfoque de derechos con un enfoque territorial. Primero porque el conflicto ha afectado más a unos territorios que a otros. Y porque ese cambio no se va a lograr si no se articulan los esfuerzos y se moviliza a la población en esos territorios alrededor de la paz. [...] Eso es lo que llamo la paz territorial (Jaramillo, 2014: 1).

Si se analiza pormenorizadamente la violencia directa y estructural asociada a los territorios más golpeados por la violencia durante los cuatro últimos años, es posible dar cuenta de las limitaciones y dificultades transformadoras que para el proceso de construcción de paz en clave territorial ha desplegado el Acuerdo con las FARC-EP. Debido a lo anterior en las siguientes páginas se intenta ahondar en cómo la violencia que se producía por el conflicto armado antes del inicio del diálogo que transcurrió en La Habana sigue aconteciendo en los mismos enclaves periféricos de entonces. Destacan, a tal efecto, los departamentos de Arauca y Norte de Santander en el nororiente; el litoral Pacífico - especialmente Chocó, Cauca y Nariño- y departamentos del sur como Caquetá o Putumayo. En estos escenarios se concentra casi el $80 \%$ de los asesinatos de líderes sociales y exguerrilleros de las FARC-EP perpetrados desde 2016, tal y como muestran los reportes de la Policía Nacional (2019) a la Consejería Presidencial para los Derechos Humanos y Asuntos Internacionales, la Misión de Verificación de Naciones Unidas (2020) y fundaciones como Indepaz (2018) ${ }^{1}$.

1. En el caso de los líderes sociales, la violencia contra estos es producto de su posición en favor del Acuerdo de Paz, lo que contraviene las fuentes de financiación ilícita o los impedimentos a la restitución de tierras afines a los grupos armados y estructuras criminales. En el caso de los exguerrilleros de las FARC-EP destacan los intentos de cooptación a la criminalidad y las actitudes de venganza frente al proceso de reincorporación a la vida civil. 
Como variables intervinientes sobre este tipo de violencia destacan varios elementos explicativos: la condición periférica irresoluta, relacionada con dinámicas de violencia estructural, la concentración de cultivo cocalero y la preeminencia de estructuras armadas y grupos criminales. La condición periférica se operacionaliza a través de elementos tales como el índice de necesidades básicas insatisfechas, de acuerdo con los datos ofrecidos por el Departamento Nacional de Estadística (2019), mientras que la condición socioeconómica y las capacidades institucionales para hacer frente a la construcción de paz son presentadas a partir de un cuestionario con una escala de Likert realizado a 246 alcaldías de todo el país. Lo anterior, bajo un muestreo aleatorio simple desarrollado por los autores justo antes de la firma efectiva del Acuerdo de Paz.

Relacionada con la violencia estructural, igualmente destaca la impronta cocalera, la cual se mide con base en las hectáreas cultivadas registradas por el Observatorio de Drogas (s. f.), adscrito a la Policía Nacional. De otro lado, las estructuras criminales y su activismo son analizados a partir de los reportes de la Policía Nacional (s. f.), el Ministerio de Defensa (2019), el Observatorio de Derechos Humanos y Derecho Internacional Humanitario ${ }^{2}$ (ODHDIH, s. f.) y fundaciones como Indepaz (2018), Fundación Ideas para la Paz (2019) o Paz y Reconciliación (2019). Unido a lo anterior, este análisis igualmente exige la consulta de los informes sobre la evolución de la implementación del Acuerdo de Paz que anualmente publica el Instituto Kroc de la Universidad de Notre Dame.

\section{LA DIMENSIÓN TERRITORIAL DEL ACUERDO DE PAZ}

El Acuerdo de Paz suscrito entre el Gobierno colombiano y las FARC-EP identificaba, entre otras cuestiones, la necesidad de intervenir sobre las condiciones socioeconómicas de los territorios que se habían visto más afectados por el conflicto armado. Varios autores han venido defendiendo desde finales de los ochenta (Sánchez, 1987; Reyes y Bejarano, 1988; Ramírez, 1990) que el conflicto no se puede entender sin integrarlo con elementos estructurales que, irresolutos, han perdurado durante décadas. No se puede obviar que Colombia ha sido uno de los países más desiguales de América Latina, tanto por su coeficiente de Gini en atención a la distribución de la renta $(0,54)$ como por la distribución de la propiedad de la tierra $(0,85)$ (Comisión Económica para América Latina, 2019). Incluso, de acuerdo con el índice de pobreza multidimensional que elabora el Programa de Naciones Unidas para el Desarrollo (2019), Colombia es uno de los diez países más desiguales del mundo; una condición en línea con lo que este mismo Programa de Naciones Unidas para el Desarrollo

2. El ODHDIH puso a disposición de los autores una base de datos sobre el conflicto armado, con desglose municipal, que abarca el período 1990-2012, posteriormente extensible hasta 2015. Esta se nutre de los boletines diarios del Departamento Administrativo de Seguridad hasta 2010, y desde 2011 de los reportes del Comando General de las Fuerzas Militares. 
(2011) señalaba hace una década, cuando reconocía que apenas el $1 \%$ de la población era propietaria de más del $50 \%$ de la superficie del país.

Teniendo en cuenta que la reforma agraria es una cuestión insatisfecha, heredada desde la fallida Ley 200 de 1936 impulsada bajo la presidencia de López Pumarejo (Legrand, 1988), para las diferentes guerrillas aquella ha sido una de las banderas que enarbolar en aras del sueño de la revolución social (Villamizar, 2017). No obstante, dada la impronta agraria de las FARC-EP, para estas siempre ha sido un elemento que considerar en cualquier eventual diálogo sostenido con el Gobierno colombiano (Pizarro, 2017).

En el punto 1 del Acuerdo de Paz se identifica la necesidad de desarrollar lo que se denomina como «reforma rural integral», la cual parte de tres principios transversales que son la erradicación de la pobreza, la formalización del acceso progresivo a la propiedad de la tierra y su democratización. Esto implícitamente pasa por la construcción y formalización de un tejido productivo en territorios que, en algunos casos, presentan niveles acuciantes de pobreza y debilidad institucional. Además, se impulsa la necesidad de mecanismos de asociatividad solidaria a través de instrumentos cooperativos o las inicialmente denominadas «zonas de reserva campesina». Todo lo anterior, en relación con la promoción de un enfoque transversal de género y multicultural que fortalezca los entornos más golpeados por la violencia.

Entre algunas medidas concretas de este punto, el Acuerdo de Paz dispone la necesidad de un "fondo de tierras» y un proceso masivo de reconocimiento de derechos. El primero queda conformado por tres millones de hectáreas provenientes de procesos de extinción judicial de dominio en favor del Estado, tierras baldías, de origen forestal, inexplotadas o donadas ex profeso al fondo, entre otros. A su vez, se insta la necesidad de una formalización masiva de otros siete millones de hectáreas, a las que se acompañan otros tantos mecanismos de apoyo jurídico e inversión, tanto en forma de créditos como de subsidios. Con el fin de desarrollar un enfoque integral de construcción de paz desde el territorio se prevén otras líneas de acción, como el desarrollo de infraestructura vial, eléctrica, de riego o la promoción de mecanismos de desarrollo social a través de la educación y la vivienda.

Estos instrumentos se acompañan de los conocidos como Planes de Desarrollo con Enfoque Territorial (PDET), cuyo propósito es la construcción de capacidades institucionales y participativas desde una mirada bottom-up. No se puede obviar que, a pesar de lo reconocido en el marco constitucional de 1991, y específicamente en artículos como el 298, 350 o 357, Colombia es un Estado descentralizado administrativamente. Sin embargo, en la realidad, como proponen trabajos como el de Estupiñán (2011), se trata de uno de los países más centralizados de América Latina. Especialmente por la concurrencia de una profunda brecha territorial que se traduce en una acentuada inelasticidad vertical de renta por la que más del $80 \%$ de los recursos del Estado se encuentran gestionados en el nivel central de Gobierno, y menos del $20 \%$ se distribuye, casi en iguales términos, entre los distritos capitales, 32 departamentos y algo más de 1100 municipios. Así, concurre una centralidad de los recursos, su planificación y destino, con una violencia que, con el paso de los años, ha sido cada 
vez más periférica (Ríos, 2016; Salas, 2016). Esta condición ha sido igualmente señalada por Ramírez y De Aguas (2017), que redundan en cómo, producto de lo anterior, se aprecia un importante rezago en los niveles de competitividad y productividad de aquellos departamentos de impronta rural y periférica frente a los centros decisorios del país como Cundinamarca, Antioquia, el eje cafetero, Santander o Valle del Cauca.

Relacionado con aquello estaría también el punto 4 del Acuerdo de Paz, relativo a la «solución al problema de las drogas ilícitas». El narcotráfico ha estado altamente vinculado con la evolución e intensificación del conflicto armado colombiano (Pécaut, 2008; Henderson, 2010). Durante algunos años de la década pasada, producto de las polémicas aspersiones con glifosato, logró reducirse la magnitud de la superficie cocalera, si bien en los últimos ańos ha tenido lugar una nueva tendencia expansiva nada desdeñable. Si en 2013 se contabilizaban 48000 ha cultivadas, la superficie de cultivos ilícitos en Colombia ha ido creciendo hasta superar actualmente las 150000 ha (Observatorio de Drogas, s. f.).

De manera particular, lo que se ha experimentado en los últimos años ha sido una consolidación de enclaves cocaleros en el sur y suroccidente colombiano (Cauca, Caquetá, Narińo y Putumayo), además de en Norte de Santander, cuya la región del Catatumbo supera actualmente las 40000 ha cocaleras (UNODC, 2020). Dada la magnitud de este fenómeno, la mitigación del cultivo ilícito y su necesaria sustitución por otros cultivos alternativos ha sido una de las prioridades del Acuerdo de Paz. Ello requiere igualmente de los estímulos recogidos en el punto 1 del mismo, aunque, como se verá con posterioridad, hasta el momento apenas se ha avanzado en la reducción del negocio cocalero y su afectación sobre las cadenas criminales.

La realidad es que el ELN y los grupos herederos del paramilitarismo son los que han terminado por consolidarse como actores de la violencia local en aquellos escenarios cocaleros en donde, hasta 2016, la presencia de las FARC-EP era hegemónica. Esto, aun cuando el Acuerdo subsume la solución del problema a la atención de las necesidades relacionadas con la reforma rural integral, aunando los cultivos alternativos con el desarrollo local y la construcción de oportunidades. Lo anterior, en aras de promover dicha sustitución bajo cauces de voluntarismo, participación y enfoques diferenciales, en coherencia con las necesidades y demandas del nivel municipal. En cualquier caso, ello no es óbice para que puedan existir programas de erradicación forzosa, pues lejos de lo que argüían algunas voces en contra del Acuerdo, este también integra la necesidad de dotar al Estado de mayores recursos para perseguir el lavado de activos y el crimen organizado asociado al narcotráfico.

Son varios los trabajos que han destacado la necesidad de atender las posibilidades y desafíos que acompañan a esta concepción de paz territorial (Cairo et al., 2018; Estupińán, 2018; Rodríguez Iglesias, 2020), y no solo con base en procesos socioeconómicos e institucionales, sino igualmente atendiendo a la recomposición del tejido social, la promoción de la reconciliación y culminación del proceso de dejación de armas y la reincorporación plena a la vida civil (McFee y Rettberg, 2019; Mouly et al., 2019). Esto, en tanto que, igualmente, la participación política del partido resultante de las extintas FARC-EP, la dejación de armas y el tránsito pacífico a la ciudadanía, la 
superación del problema de las drogas ilícitas o el componente de víctimas previsto en el Acuerdo responden a una mirada territorial desde el nivel local que explica la importancia de los trabajos académicos que entre 2016 y 2020 se han centrado en reflexionar y problematizar las posibilidades reales de una verdadera paz territorial en Colombia (Lemaitre y Restrepo, 2019; Ahumada, 2019; Cairo y Ríos, 2019; Le Billon et al., 2020).

\section{VIOLENCIA TERRITORIAL Y CONDICIÓN PERIFÉRICA}

Entre algunos de los trabajos centrados en la evolución territorial del conflicto armado, existen aportaciones como las de Echandía (2006), Echandía y Cabrera (2017), Salas (2010, 2016), Ríos (2016, 2021) o Ríos et al., (2019), que muestran la manera en que se ha ido transformando la geografía de la violencia en Colombia, respondiendo a una lógica de periferialización, por la que los diferentes grupos armados y estructuras criminales han terminado consolidando su posición en enclaves geográficos hostiles, alejados de los centros económicos y políticos decisorios del país. Estos escenarios coinciden en presentar una orografía difícil para el despliegue de operativos y acciones por parte de la Fuerza Pública, habida cuenta de una condición selvática y/o montañosa notable, que generalmente se acompaña de corredores de índole fronteriza que coadyuvan las lógicas de resistencia de los diferentes grupos armados.

Este argumento invita a entender que los escenarios que tradicionalmente han servido de escenario para la supervivencia de las FARC-EP, el ELN o Los Pelusos ${ }^{3}$, apenas se han visto transformados por una implementación deficitaria del Acuerdo de Paz, que ha puesto de manifiesto la incapacidad del Estado para llegar a según qué territorios -en donde la concurrencia de grupos armados y estructuras criminales ha sido notable- . Si se toman las cifras del ODHDIH (s. f.) relacionadas con el conflicto armado para el año 2012, se puede observar cómo, sobre un total de 824 acciones armadas protagonizadas por las FARC-EP, los departamentos con mayor activismo guerrillero fueron Antioquia (96), Arauca (57), Caquetá (64), Cauca (161), Nariño (73), Norte de Santander (74) y Putumayo (70). Algo similar se aprecia para el caso del ELN, que con un impacto mucho menor (71), condensa sus operativos en Arauca (26), Norte de Santander (11), Narińo (9), Chocó (8) y Cauca (4). En ambos casos se aprecia una predisposición a la violencia en departamentos fronterizos y corredores periféricos del nororiente (frontera con Venezuela), del sur y del suroccidente (frontera con Ecuador y Perú) y de la región Pacífico.

3. Los Pelusos es un grupo criminal que se considera continuador del Ejército Popular de Liberación, creado en 1967 en la región del Urabá antioqueño y chocoano. Se desmovilizó en 1991, aunque un pequeño remanente se mantuvo operativo y se reubicó en la región del Catatumbo, en Norte de Santander. Allí se ha consolidado gracias a los beneficios provenientes del narcotráfico. Bajo la directiva 015 de 2016 del Ministerio de Defensa, se negó su condición guerrillera y es tratado como un grupo narcotraficante. 
MAPa 1.

Presencia de las FARC-EP y el ELN, 2012
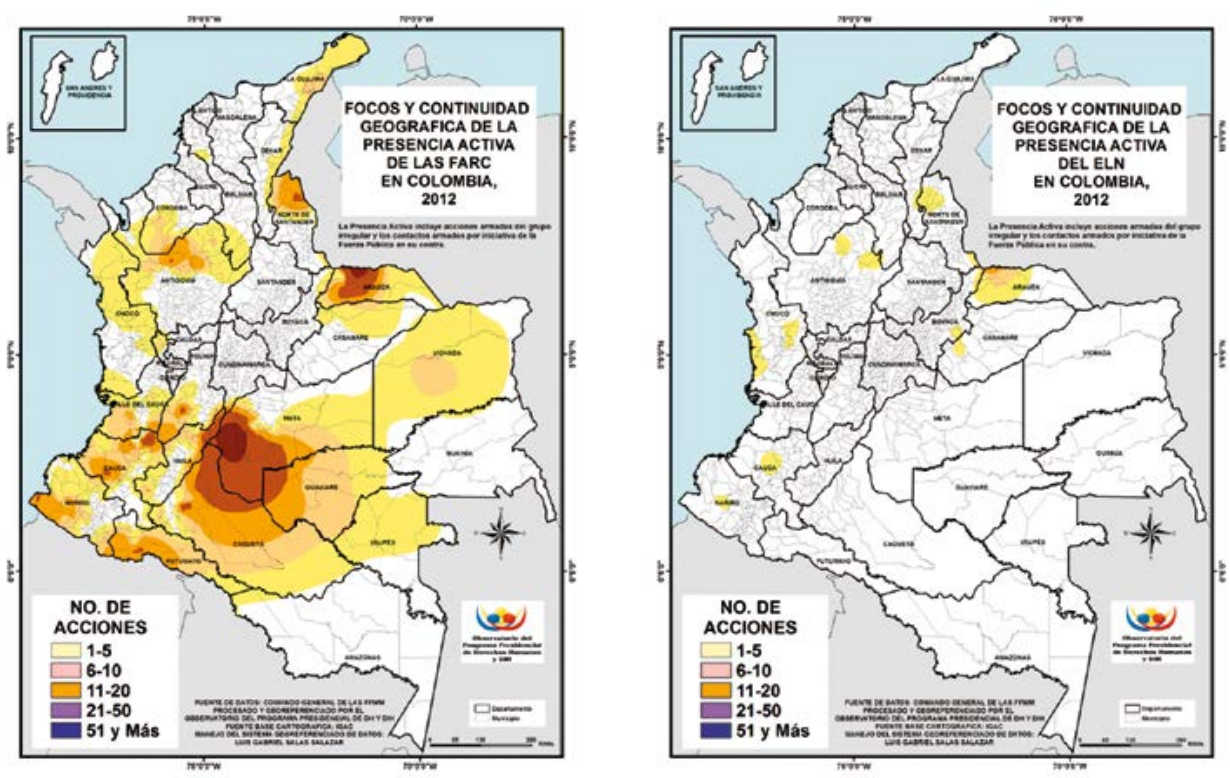

Fuente: ODHDIH (s. f.).

Tomando como segundo registro el año 2015, se observa una dinámica idéntica, aun cuando el proceso de diálogo estaba a punto de cerrarse con las FARC-EP y con el ELN se avanzaba positivamente en la posibilidad de abrir un escenario paralelo de negociación. El mismo ODHDIH (s. f.) registraba hasta 122 acciones guerrilleras, de las cuales 94 correspondían a las FARC-EP y 28 al ELN. A pesar de la desescalada del conflicto armado, las dinámicas territoriales eran muy parecidas a las de 2012. En el caso de las FARC-EP, los departamentos con mayor activismo volvían a ser Antioquia (22), Arauca (8), Cauca (20), Caquetá (2), Nariño (15), Norte de Santander (12) y Putumayo (6). Igualmente, el ELN focalizaba su presencia sobre Arauca (10), Norte de Santander (9), Bolívar (5), Cauca (2) y Nariño (2).

En relación con lo expuesto, parece plausible plantear que, a excepción de Antioquia - que es un departamento con dinámicas de violencia particulares (García de la Torre y Aramburo, 2011), antes y durante el proceso de diálogo transcurrido en La Habana-, la geografía de la violencia guerrillera en Colombia venía presentando un especial arraigo en aquellos enclaves periféricos del nororiente, del sur y del suroccidente y, en menor medida, en Bolívar y Chocó. En la actualidad, si se observan las cifras producidas por la violencia del ELN, Los Pelusos o las disidencias de las extintas FARC-EP y otros nuevos grupos criminales, se puede observar cómo la condición periférica persiste irresoluta. De acuerdo con los datos que ofrece la Policía Nacional (2019), entre enero de 2017 y diciembre de 2018 se contabilizaron en Colombia un 
total de 29 acciones subversivas contra este cuerpo por parte del ELN, de las cuales, la mayoría se dieron en Arauca (11), Norte de Santander (5), Bolívar (4) y Cauca (4). De los 198 actos de terrorismo contabilizados en idéntico período de tiempo, la condición periférica se presenta inalterada, pues entre los departamentos más afectados por este fenómeno de violencia destacan, junto a Antioquia (33), Arauca (21), Cauca (17) y Nariño (31).

No obstante, a estos departamentos cabría añadir otros en donde la violencia ha ido paulatinamente en aumento, como sucede en Meta (23), producto del incremento de disidencias de las FARC-EP, o en Cesar (17) y Bolívar (4), dada la mayor presencia del ELN y de Los Pelusos. Esto también se pone de manifiesto en uno de los reportes recientemente publicados por la Fundación Ideas para la Paz (2020), según el cual se llegan a contabilizar un total de 211 acciones armadas del ELN por 163 combates de la Fuerza Pública entre enero de 2016 y diciembre de 2018. Todos ellos estarían condensados, en más de un $80 \%$, en los departamentos fronterizos con Venezuela de Arauca, Norte de Santander y Cesar, por una parte, y en Antioquia y los departamentos de la región Pacífico, de Chocó, Cauca y Nariño, por otra.

La desaparición de las FARC-EP del tablero del conflicto armado no supone que algunos vestigios de la extinta guerrilla no sigan presentes, ya sea por una renuencia primigenia a aceptar el Acuerdo de Paz y desmovilizarse o porque se han conformado estructuras criminales emergentes que, aprovechando la continuidad de la violencia, han conseguido nuevas movilizaciones en favor de la criminalidad. Si se observan las estructuras disidentes de mayor calado en la actualidad, otra vez se aprecia el componente periférico descrito.

\section{Mapa 2.}

Presencia de los PRinCipales grupos ARMAdos, 2020

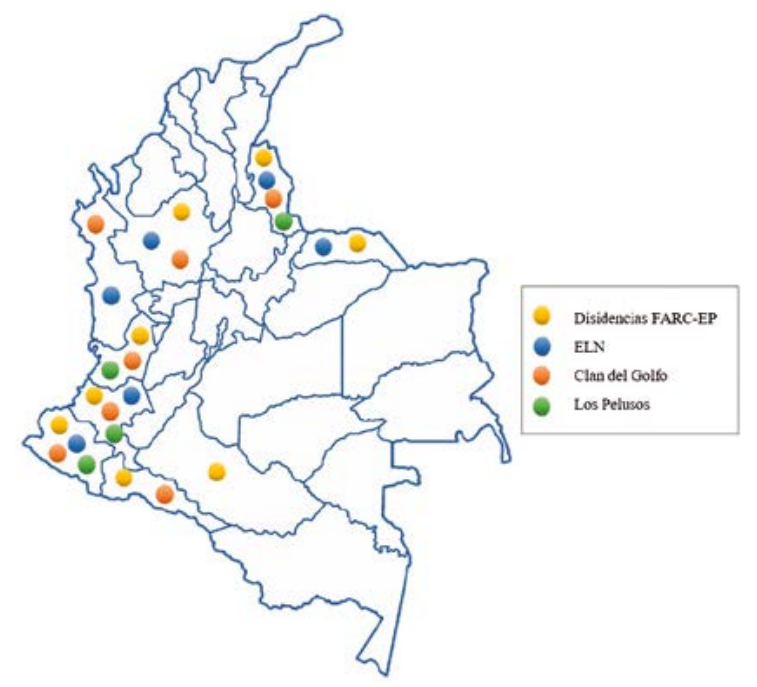

Fuente: elaboración propia. 
En la región del Pacífico los principales actores armados son disidencias y remanentes de viejas estructuras de las FARC-EP. En Cauca y Valle del Cauca hay remanentes organizados herederos del Frente 6, Frente 8, Frente 30 y las columnas Miller Perdomo y Jacobo Arenas. En Narińo hay una importante atomización de estructuras criminales que guardan relación con el viejo Frente 29 de las FARC-EP y la Columna Daniel Aldana, tal y como sucede con estructuras armadas como el Óliver Sinisterra, Resistencia Campesina o Defensores del Pacífico. En el sur del país han ganado relevancia algunos remanentes de los antiguos Frentes 14 y 15 en Caquetá, y del Frente 48 en Putumayo. Mientras, en el nororiente colombiano destacan grupos herederos del Frente 10 en Arauca y del Frente 33 en Norte de Santander. Finalmente, en Antioquia hay presencia de estructuras herederas del Frente 18 y del Frente 36 de las FARC-EP (Indepaz, 2018; Fundación Ideas para la Paz, 2019; Fundación Paz y Reconciliación, 2019).

A estos grupos criminales cabría añadir otros frentes que optaron desde el inicio por mantenerse al margen de la negociación, como el Frente 1, activo en el sur del país (Caquetá, Amazonas, Vaupés), pero también en departamentos como Meta y Vichada; o el Frente 7, presente en Vichada o Guainía. Y ello sin desatender a los repuntes de violencia en el departamento del Meta, producto de grupos que enarbolan la bandera de los antiguos Frente 30 y 62 de las FARC-EP (Indepaz, 2018; Fundación Ideas para la Paz, 2019; Fundación Paz y Reconciliación, 2019). Por otra parte, hay que tener en cuenta a Los Pelusos, cuyo activismo, conformado por unos doscientes combatientes, gravita en torno a la región del Catatumbo, en Norte de Santander. Sin embargo, existe constancia de que en los últimos años han conseguido salir de su tradicional arraigo cocalero y desarrollar acciones armadas residuales en Cesar, Valle del Cauca y Nariño.

Quedaría hacer referencia al grupo criminal del Clan del Golfo, también denominado como Autodefensas Gaitanistas de Colombia. El fenómeno postparamilitar comenzado en 2008, a partir del rearme por mandos medios de algunas estructuras de las extintas Autodefensas Unidas de Colombia (AUC), tuvo un inicial arraigo en la región Caribe, el litoral Pacífico y el departamento de Antioquia. Estas estructuras criminales terminaron extendiendo su control territorial, de manera que en la actualidad, si bien es cierto que su presencia municipal ha decaído con respecto a hace unos años, sigue afectando a más de doscientos municipios, principalmente, de las tres regiones mencionadas (Ministerio de Defensa, 2019).

Aunque en la actualidad concurren una veintena de estructuras criminales, el Clan del Golfo, con más de 1800 integrantes, llega a condensar casi las dos terceras partes de los efectivos al servicio de estos grupos delincuenciales. Su paulatina fractura en grupúsculos más pequeños se ha visto acelerada por la ventana de oportunidad que territorialmente ha supuesto el abandono de las armas de las FARC-EP. Así, los departamentos del nororiente, de la región Pacifico y del sur del país han sido especialmente atractivos para el incremento de sus redes de financiación ilícita y su actividad delictiva.

Este grupo armado ha protagonizado importantes enfrentamientos con el ELN en Chocó, y con las disidencias de las FARC-EP en Cauca y Nariño, toda vez que en los enclaves portuarios de Barranquilla y Cartagena han mantenido disputas con Los 
Pachenca e, igualmente, en el Bajo Cauca y el norte antioqueño con los Caparrapos y el ELN. Incluso, una alianza entre esta guerrilla, el Frente 33 de las FARC-EP y Los Pelusos, terminó restringiendo su capacidad operativa en la región cocalera del Catatumbo (Echandía y Cabrera, 2018). Esta situación se extendería a departamentos como Meta, Casanare o Vichada, donde el repunte de las disidencias de las FARC-EP ha conducido a importantes confrontaciones por el control del recurso cocalero con Frentes como el 1 o el 7 (Indepaz, 2018; Fundación Ideas para la Paz, 2019; Fundación Paz y Reconciliación, 2019).

\section{MAPA 3.}

Departamentos Con mayor Número de asesinatos a eXguerrilleros de las FARC-EP, 2OI7-2020

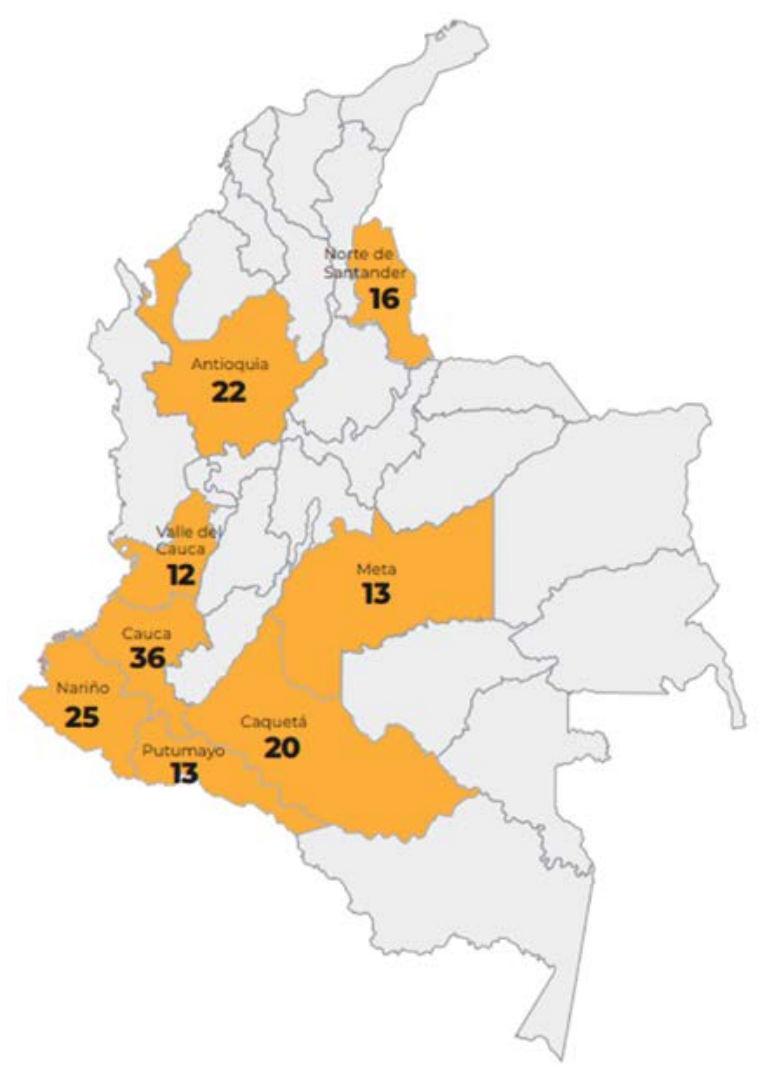

Fuente: Misión de Verificación de las Naciones Unidas en Colombia (2020: 2).

Lo expuesto guarda una absoluta relación con la producción de violencia dirigida, en el marco de implementación del Acuerdo de Paz, contra líderes sociales y exguerrilleros de las FARC-EP. Según las cifras de la Consejería Presidencial para los Derechos Humanos y Asuntos Internacionales (2020) y el Mecanismo de Seguimiento de Naciones Unidas 
(2020), son casi 400 líderes y 200 excombatientes $^{4}$ los asesinados desde la firma del Acuerdo hasta el mes de abril de 2020. De hecho, no es casualidad que de los 194 exguerrilleros de las FARC-EP asesinados hasta la publicación del primer informe de la Misión de Verificación de Naciones Unidas, a finales de marzo de 2020, más de tres cuartas partes hayan sido en departamentos en donde se condensa el mayor número de estructuras criminales: Cauca (36), Nariño (25), Antioquia (22), Caquetá (20), Norte de Santander (16), Putumayo (13), Meta (13), Valle del Cauca (12) y Chocó (5).

Algo parecido sucede con el número de líderes sociales asesinados. De acuerdo con el Informe de homicidios contra lideres sociales y defensores de derechos humanos (2020), enriquecido por los datos de la Policía Nacional, entre la firma del Acuerdo con las FARC-EP y el 31 de diciembre de 2019 se habrían contabilizado en Colombia un total de 365 asesinatos. La mayor parte de ellos se daría en Cauca (60), Antioquia (53), Valle del Cauca (35), Caquetá (21), Norte de Santander (32), Nariño (19), Arauca (15) Putumayo (15) y Chocó (12). No obstante, a estos podrían sumarse los sucedidos en 2020, y que Indepaz (2020) eleva hasta los 150 casos, perteneciendo el $80 \%$ de los casos a los mismos departamentos referidos: Cauca (47), Antioquia (19), Putumayo (13), Norte de Santander (11), Valle del Cauca (10) y Narińo (7), y en menor medida, Chocó (4), Caquetá (3), Arauca (1).

Dicho esto, cabría pensar en un ejercicio correlacional que ilustre la relación causal entre estructuras criminales y violencia homicida relacionada con el Acuerdo de Paz. Esta podría entenderse a partir de la suma del número de muertes de exguerrilleros de las FARC-EP $(x)$ y el número de muertes de líderes sociales $(y)$, tal y como reza la siguiente ecuación:

La otra parte del ejercicio correlacional tendría en consideración la particular presencia de grupos armados y estructuras criminales que, con base en lo argüido, se asientan en la periferia colombiana, tal y como recoge la tabla 1:

TABLA 1.

NÚMERO DE ESTRUCTURAS ARMADAS POR DEPARTAMENTO

\begin{tabular}{lccccc}
\hline Departamento & Disidencias FARC-EP & ELN & $\begin{array}{c}\text { Clan del } \\
\text { Golfo }\end{array}$ & $\begin{array}{c}\text { Los } \\
\text { Pelusos }\end{array}$ & Total \\
\hline Cauca & $\begin{array}{c}\text { Dagoberto Ramos } \\
\text { Frente } 30 \\
\text { Jaime Martínez } \\
\text { Jacobo Arenas }\end{array}$ & $\begin{array}{c}\text { F. G. } \\
\text { Suroccidente }\end{array}$ & Sí & Sí & 7 \\
Nariño & $\begin{array}{c}\text { Oliver Sinisterra } \\
\text { Resistencia Campesina } \\
\text { Defensores del Pacífico }\end{array}$ & $\begin{array}{c}\text { F. G. } \\
\text { Suroccidente }\end{array}$ & Sí & Sí & 6 \\
\hline
\end{tabular}

4. Según Indepaz (2020), la muerte de líderes sociales supera los 700. A mediados de junio de 2020 ya se habían superado las 200 víctimas mortales de exguerrilleros de las FARC-EP. 


\begin{tabular}{lccccc}
\hline Departamento & Disidencias FARC-EP & ELN & $\begin{array}{c}\text { Clan del } \\
\text { Golfo }\end{array}$ & $\begin{array}{c}\text { Los } \\
\text { Pelusos }\end{array}$ & Total \\
\hline Valle del Cauca & $\begin{array}{c}\text { Frente } 30 \\
\text { Defensores del Pacífico } \\
\text { Jaime Martínez } \\
\text { Jacobo Arenas }\end{array}$ & No & Sí & Sí & 6 \\
\hline Antioquia & $\begin{array}{l}\text { Frente } 18 \\
\text { Frente } 36\end{array}$ & $\begin{array}{c}\text { F. G. Darío } \\
\text { Ramírez Castro }\end{array}$ & Sí & No & 4 \\
\hline Caquetá & $\begin{array}{l}\text { Frente } 1 \\
\text { Frente } 14\end{array}$ & No & No & No & 3 \\
\hline Forte de Santander & Frente 15 & F. G. 33 & Sí & Sí & 4 \\
\hline Chocó & No & F. G. Occidental & Sí & No & 2 \\
\hline Putumayo & Frente 48 & No & Sí & No & 2 \\
\hline Arauca & Frente 10 & F. G. Oriental & No & No & 2 \\
\hline
\end{tabular}

Fuente: elaboración propia a partir de los reportes de la Policía Nacional y el Ministerio de Defensa.

De este modo, el resultado de la suma de muertes de exguerrilleros y líderes sociales, a través de una correlación de Pearson ${ }^{5}$ y relacionando el número de estructuras criminales presentes, muestra un coeficiente que, como se puede observar en la tabla 2, arroja un resultado positivo y significativo a la hora de observar la relación entre ambas variables. Esto dejaría entrever el particular impacto del conflicto en la geografía de la violencia periférica, según el cual a mayor cantidad de grupos criminales - mayormente dedicados al negocio del narcotráfico, como se verá a continuación - existe una mayor tendencia al homicidio de exguerrilleros de las FARC y de líderes sociales. Lo anterior, producto de la disputa por el control de las economías ilícitas o las resistencias al desarrollo de políticas de restitución de tierras o sustitución de cultivos ilícitos, entre otras cuestiones.

TABLA 2.

CORRELACIÓN de PeARSON ENTRE VIOLENCIA ASOCIADA AL CONFLICTO Y ESTRUCTURAS CRIMINALES

\begin{tabular}{llcc}
\hline & & Violencia & Est_criminals \\
\hline \multirow{3}{*}{ Violencia } & Correlación de Pearson & 1 &, $733^{*}$ \\
\cline { 2 - 4 } & Sig. (bilateral) & &, 025 \\
\cline { 2 - 4 } & $\mathrm{N}$ & 9 & $\ldots / \ldots$
\end{tabular}

5. La correlación de Pearson mide el grado de covariación, como es el caso, entre dos variables aleatorias cuantitativas que se relacionan linealmente. 


\begin{tabular}{llcc} 
& & & \\
\hline \multirow{3}{*}{ Est_criminals } & Correlación de Pearson &, $733^{*}$ & Est_criminals \\
\cline { 2 - 4 } & Sig. (bilateral) &, 025 & \\
\cline { 2 - 4 } & $\mathrm{N}$ & & 9 \\
\hline
\end{tabular}

* La correlación es significativa en el nivel 0,05 (bilateral).

Fuente: elaboración propia.

\section{VIOLENCIA ESTRUCTURAL Y NEGOCIO COCALERO}

Entre los elementos que caracterizan a los departamentos periféricos analizados, además de una marcada impronta fronteriza y distante de los principales centros económicos y políticos del país, coinciden otros aspectos que tienen que ver con condiciones socioeconómicas y capacidades institucionales muy endebles, cooptadas en buena medida por la prevalencia de economías ilícitas, como las provenientes del narcotráfico ${ }^{6}$. Los autores de esta investigación realizaron 246 encuestas sobre un total de 1123 alcaldías entre 2014 y $2015^{7}$, a partir de un muestreo aleatorio simple, con el objetivo de medir las percepciones de las alcaldías respecto a la violencia estructural de sus municipios y las capacidades institucionales frente al postconflicto armado. Nuevamente, se parte de que los departamentos con mayor impacto de la violencia son los mismos enclaves periféricos del litoral Pacífico, el sur y suroccidente colombiano y los departamentos del nororiente, como Arauca y Norte de Santander —además de Antioquia- A todos los alcaldes y alcaldesas se les pedía, a partir de una escala Likert (1-10), que valorasen los principales problemas que debían afrontar sus alcaldías y las capacidades socioeconómicas e institucionales disponibles para afrontar un eventual proceso de construcción de paz desde el territorio. Los resultados pueden verse en las tablas 3 y 4.

Esta situación de debilidad institucional, de escasas capacidades económicas y de reducidas expectativas del posconflicto, cabría esperar que ha sido matizada tras casi cuatro ańos de la firma del Acuerdo de Paz. Sin embargo, si lo anterior se contrasta con el avance recogido en los sucesivos informes publicados por el Instituto Kroc de la Universidad de Notre Dame, no parece apreciarse un alto grado de cumplimiento al respecto.

Durante los dos primeros ańos de este proceso, la prioridad fue el abandono de las armas, el cese del fuego definitivo, la preparación de la arquitectura institucional para

6. Algunos trabajos han arrojado luz, por ejemplo, a la relación del conflicto con la minería ilegal (Rettberg et al., 2018; Rettberg y Ortiz, 2018).

7. Una confianza del $95 \%$ y un error muestral del $5 \%$ hubiera requerido un total de 286 encuestas. Esto implica que la confianza del $95 \%$ se acompaña, finalmente, de un 5,5\% de error muestral. 
TABLA 3.

VALORACIÓN DE LAS ALCALDÍAS DE LOS PRINCIPALES PROBLEMAS DE SU MUNICIPIO, 2OI 5

\begin{tabular}{lcccccc}
\hline & Desempleo & Pobreza & Inequidad & $\begin{array}{c}\text { Ausencia } \\
\text { del Estado }\end{array}$ & Corrupción & $\begin{array}{c}\text { Cultivos } \\
\text { ilícitos }\end{array}$ \\
\hline Arauca & 6.80 & 6.28 & 6.00 & 7.00 & 2.0 & 2.0 \\
\hline Caquetá & 8.33 & 8.33 & 7.66 & 8.66 & 5.0 & 9.3 \\
\hline Cauca & 7.16 & 7.40 & 5.75 & 5.62 & 2.87 & 5.62 \\
\hline Chocó & 9.0 & 7.75 & 7.0 & 7.75 & 2.25 & 5.75 \\
\hline Narińo & 7.23 & 7.83 & 6.33 & 8.0 & 6.16 & 5.66 \\
\hline Norte de Santander & 8.0 & 7.5 & 6.5 & 9.0 & 3.0 & 7.0 \\
\hline Putumayo & 9.0 & 9.0 & 6.0 & 8.0 & 2.0 & 8.0 \\
\hline Valle del Cauca & 7.0 & 5.85 & 4.57 & 5.28 & 3.42 & 4.57 \\
\hline Media nacional & 6.53 & 6.50 & 5.81 & 5.37 & 4.01 & 3.74 \\
\hline
\end{tabular}

Fuente: elaboración propia.

Tabla 4.

CAPACIDADES INSTITUCIONALES Y PRESENCIA DE GRUPOS ARMADOS, 2015

\begin{tabular}{lccccccc}
\hline & $\begin{array}{c}\text { Capacidades } \\
\text { institucionales }\end{array}$ & $\begin{array}{c}\text { Capacidades } \\
\text { socioeconómicas }\end{array}$ & $\begin{array}{c}\text { Expectativas } \\
\text { postconflicto }\end{array}$ & $\begin{array}{c}\text { Presencia } \\
\text { de grupos } \\
\text { armados }\end{array}$ & FARC-EP & ELN & Bacrim \\
\hline Arauca & 5.1 & 4.70 & 3.0 & 8.75 & 10 & 10 & 4 \\
\hline Caquetá & 4.75 & 5 & 3.5 & 10 & 10 & 1 & 1.5 \\
\hline Cauca & 5.33 & 4.70 & 4.0 & 7.1 & 5.77 & 3 & 1.66 \\
\hline Chocó & 4.33 & 5 & 3.33 & 7.75 & 5.66 & 5.33 & 2 \\
\hline Nariño & 4.57 & 5.20 & 3.14 & 6.96 & 6.71 & 4.14 & 5.57 \\
\hline $\begin{array}{l}\text { Norte de } \\
\text { Santander }\end{array}$ & 4.66 & 4.17 & 2.33 & 8.3 & 6.5 & 5.75 & 2.25 \\
\hline Putumayo & 5.0 & 5 & 3.0 & 8.0 & 9 & 1 & 7.66 \\
\hline $\begin{array}{l}\text { Valle del } \\
\text { Cauca }\end{array}$ & 5.25 & 5.40 & 4.33 & 7.57 & 5.28 & 1.71 & 7.57 \\
\hline $\begin{array}{l}\text { Media } \\
\text { nacional }\end{array}$ & 6.53 & 6.37 & 6.50 & 5.04 & 3.43 & 1.99 & 3.36 \\
\hline
\end{tabular}

Fuente: elaboración propia.

la implementación del Acuerdo y la creación de los planes y programas previstos en el mismo. Mientras, el año 2019 se esperaba que fuese el del impulso de los compromisos con la guerrilla, aunque, con un avance general del 6\%, ha sido el ejercicio en el que menos se ha avanzado en el cumplimiento de lo acordado con las FARC-EP (Instituto Kroc, 2020). Con varios meses de retraso, en 2019, el actual Gobierno de Iván Duque concluyó, en el marco de lo establecido por los PDET, lo relativo a los 
dieciséis planes de acción para la Transformación Regional y su correspondiente hoja de ruta, y que se añade al Programa de Desarrollo con Enfoque Territorial Étnico para el departamento de Chocó, firmado en agosto de 2018. También se adelantó en la materialización del catastro de tierras, al conseguirse un préstamo proveniente del Banco Mundial y del Banco Interamericano de Desarrollo por valor de 150 millones de dólares. Empero, estos son los únicos avances reseñables para el punto 1 del Acuerdo de Paz, en tanto que de lo esperado al respecto poco más ha sido realizado, más allá de la incorporación de 700000 ha al Fondo Nacional de Tierras, que ya ha conseguido comprometer 925000 ha de las 3000000 previstas (Instituto Kroc, 2020).

\section{TABLA 5.}

Grado de cumplimiento del Acuerdo de Paz (enero 20i7-diciembre 20i9) 60

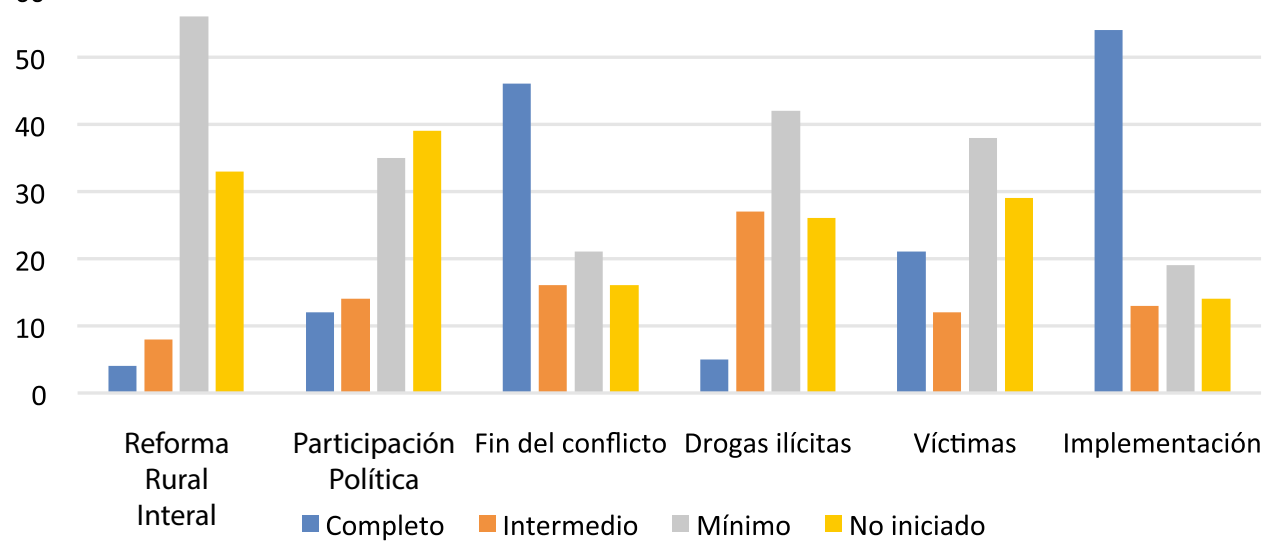

Fuente: elaboración propia a partir de los datos del Instituto Kroc (2020).

TABLA 6.

Grado de cumplimiento del Acuerdo de Paz en relación específica con la reforma RURAL INTEGRAL

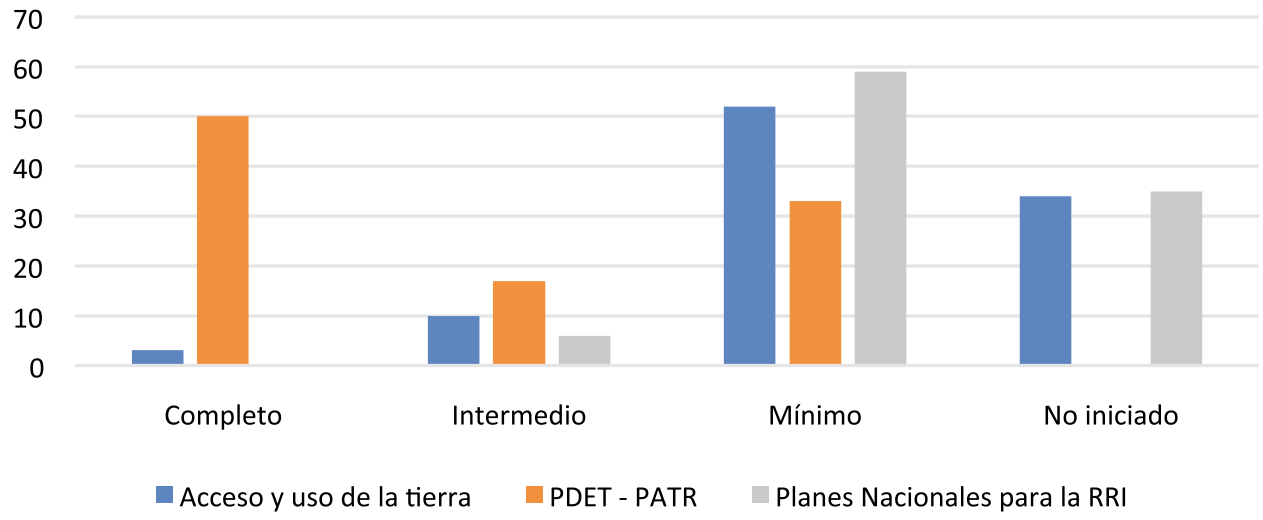

Fuente: elaboración propia a partir de los datos del Instituto Kroc (2020). 
De las 104 disposiciones comprometidas en el Acuerdo de Paz, en diciembre de 2018 solo se habían cumplido un $2 \%$, mientras que en 2019 se progresó, muy lentamente, en otro $2 \%$. Además, se ha obtenido un $8 \%$ de avance intermedio, un $56 \%$ se encuentra en desarrollo de mínimos y un $33 \%$ ni siquiera ha comenzado. Comparado con el resto de puntos del Acuerdo, este y el relacionado con el problema del narcotráfico (punto 4 del Acuerdo) son los que menos han avanzado, lo que afecta negativamente a la construcción de una verdadera paz territorial. Ello contrasta con los avances en materia de participación política (punto 2 del Acuerdo), que para 2019 presentaba un grado de cumplimiento absoluto del $12 \%$, mientras que para los puntos 3 (fin del conflicto) y 5 (víctimas) se eleva por encima del $45 \%$.

Atendiendo a lo expuesto, no cabe esperar que en la geografía de la violencia colombiana los aspectos estructurales y socioeconómicos hayan cambiado sustancialmente en lo que a desarrollo socioeconómico, umbrales de pobreza o necesidades básicas insatisfechas se refiere. Esto, ya sea por razones estructurales, como sucede en los departamentos del Pacífico o del sur del país, o por factores coyunturales, como la profunda presión migratoria y fronteriza que en los últimos años ha sido especialmente significativa en Norte de Santander y Arauca.

De acuerdo con las cifras actualizadas que ofrece el Departamento Nacional de Estadística (2019), con la excepción del Valle del Cauca (6,18\%), por el factor distorsivo que supone la ciudad de Cali, todos los departamentos objeto de estudio en este trabajo presentan niveles muy superiores al promedio nacional del índice de necesidades básicas insatisfechas, ubicado en el 14,13\%. En los casos de Chocó (65,40\%), Arauca (32,26\%), Caquetá (23,48\%), Nariño (21,59\%), Cauca (18,27\%), Norte de Santander $(18,26 \%)$ y Putumayo $(18,41 \%)$ se aprecian valores muy por encima del nivel nacional, lo que se inscribe en una importante brecha centro-periferia. Así, en departamentos centrales como Cundinamarca (6,26\%), Quindío (6,73\%), Risaralda $(8,14 \%)$, Caldas $(8,91 \%)$, Santander $(9,45 \%)$, Boyacá $(10,04 \%)$, Antioquia $(10,67 \%)$, Tolima $(12,06 \%)$, Huila $(12,68 \%)$ o Meta $(13,31 \%)$, se observan los mejores niveles de infraestructura y necesidades básicas cubiertas, toda vez que, a medida que se avanza en la condición periférica, los indicadores empeoran. Y no solo en relación con los enclaves que presentan mayor nivel de violencia guerrillera y de grupos disidentes de las FARC-EP, sino también donde mayor resulta la presencia del postparamilitarismo, como en la región Caribe: Cesar (22,82\%), Magdalena $(26,50 \%)$, Bolívar $(26,56 \%)$, Sucre $(28,98 \%)$, Córdoba $(34,82 \%)$ o La Guajira $(53,01 \%)$.

Junto a esta situación de debilidad institucional y de escasas capacidades socioeconómicas, hay que añadir un segundo componente como es el negocio cocalero y el narcotráfico, que conectan con la presencia de estructuras criminales y violencia asociada al Acuerdo de Paz. Conviene recordar que para las FARC-EP, como señala Aguilera (2010), los ingresos provenientes de la droga llegaron a representar la principal fuente de ingresos de los más de 1300 millones de dólares que cada año obtenía la guerrilla. Unas estimaciones que Bejarano y Pizarro (2003) o la Junta de Inteligencia Conjunta (2005) han elevado por encima del $50 \%$, y que se completan, principalmente, con el secuestro 
y la extorsión. En el caso del ELN, aunque fue una guerrilla más renuente al negocio cocalero, al menos hasta inicios de la década del 2000, es igualmente incuestionable su dependencia respecto de este en los últimos años, como igual sucede con los diferentes grupos paramilitares, cuyas finanzas se nutrieron del narcotráfico, así como del despojo masivo de tierras y los negocios agroextensivos.

MAPA 4.

Distribución del Cultivo cocalero en Colombia, 20io-20i9

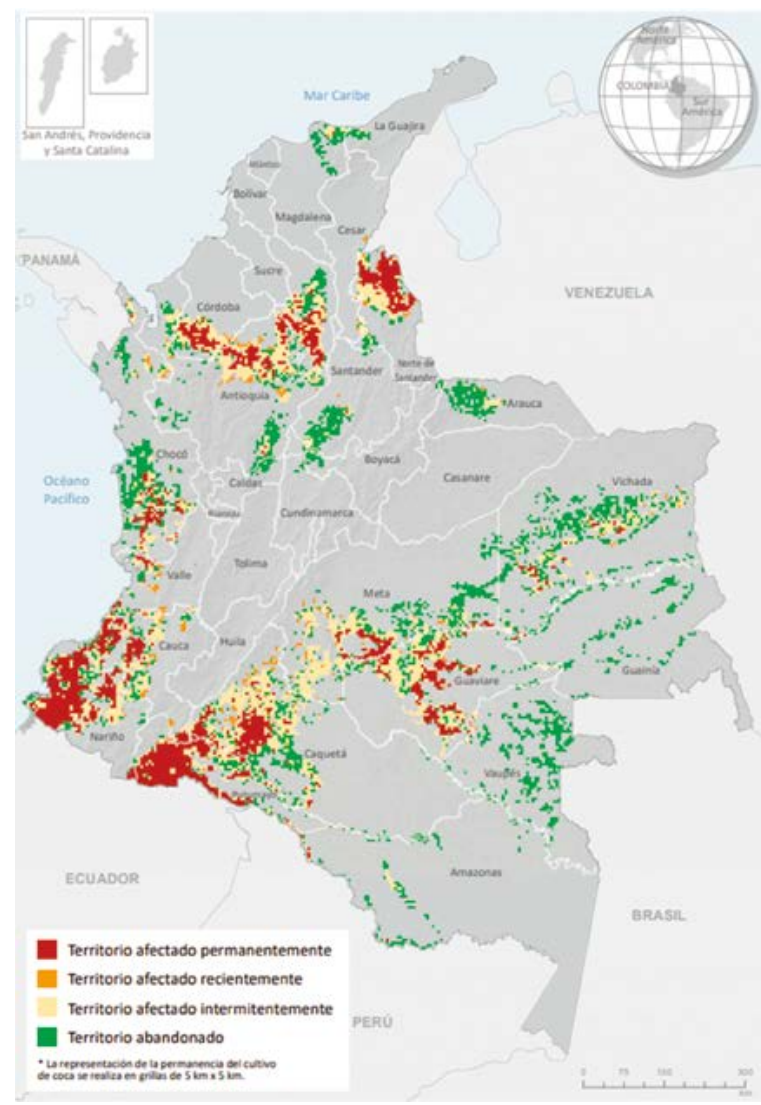

Fuente: UNODC (2020: 30).

A medida que el Estado se fue fortaleciendo en su dimensión militar y de control territorial (Medellín y Rangel, 2010), y una vez desmovilizadas las AUC a partir de 2005, las capacidades de extorsión y secuestro en la guerrilla se vieron notablemente afectadas, aumentando así la dependencia del negocio cocalero. Según el ODHDIH (s. f.), hacia 2002 las FARC-EP tenían presencia en un total de 346 municipios, de los cuales solo en 66 había cultivos de coca. En 2007, los municipios con presencia guerrillera se habían reducido a más de la mitad (152), toda vez que 64 mantenían una 
impronta cocalera. Cinco años después, hacia 2012, de los 190 municipios con presencia de las FARC-EP, en 90 se registraban cultivos ilícitos y, por ejemplo, en 2015, de los 62 municipios con presencia guerrillera, 47 guardaban una condición cocalera (id.)

En el caso del ELN la tendencia resulta similar. En 2002, la guerrilla tenía presencia en 65 municipios de los que solo en 19 se registraban cultivos ilícitos. En 2007, fuertemente hostigados por la Política de Seguridad Democrática, reducen su presencia a 18 municipios, de los cuales 10 son cocaleros. En 2012, en pleno proceso de recomposición, su presencia afecta a un total de 31 municipios, de los cuales 18 tienen cultivos ilícitos, y en 2015, de los 17 municipios con activismo del ELN, 13 mantenían esta condición (id.). Expresado de otra forma, si en 2001 la relación de municipios frente a municipios con impronta cocalera era del $40 \%$ en el caso de las FARC-EP y del $35 \%$ en el caso del ELN, para 2015 esta proporción supera el $70 \%$. En cuanto a las acciones armadas, si en 2001, sobre el total de acciones de las FARC-EP y el ELN, solo el $30 \%$ y el $23 \%$ respectivamente fueron desarrolladas sobre escenarios cocaleros, para 2015 esa proporción superaba el $75 \%$.

De acuerdo con lo expuesto, se entiende que uno de los puntos más importantes del Acuerdo de Paz suscrito con las FARC-EP fuese el relativo a la solución de las drogas ilícitas y, en particular, la reducción del impacto del negocio cocalero sobre la violencia desplegada en Colombia. Sin embargo, este segundo gran componente que tiene que ver con la paz territorial, como sucedía con la reforma rural integral, igualmente presenta un reducido nivel de implementación.

\section{TABLA 7.}

Grado de cumplimiento del Acuerdo de Paz en relación específica con la solución DE LAS DROGAS ILÍ́CITAS

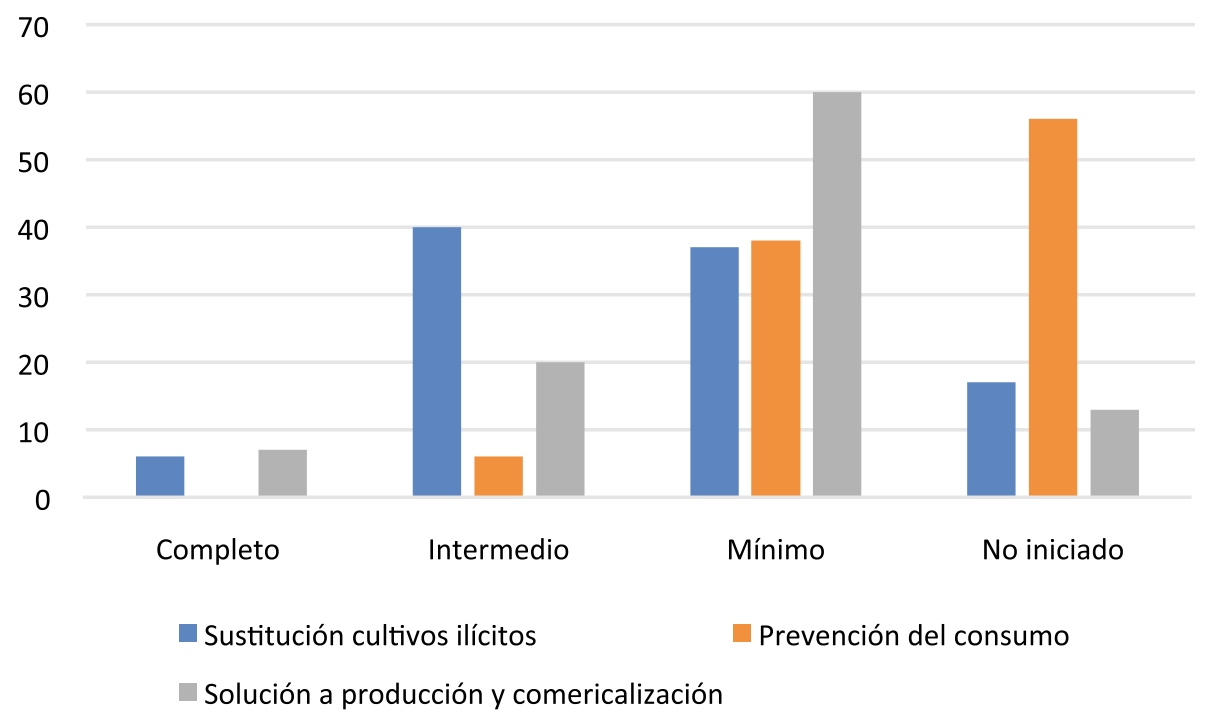

Fuente: elaboración propia a partir de los datos del Instituto Kroc (2020). 
Por ejemplo, el Programa Nacional Integral para la Sustitución de Cultivos de Uso Ilícito ha sufrido importantes retrasos en su funcionamiento, a lo que hay que añadir la dificultad de una interlocución efectiva con la sociedad civil y la violencia desplegada por las estructuras criminales, especialmente dirigida sobre los líderes sociales que en el nivel local reclaman la correcta implementación del Acuerdo frente a la corrupción, el lavado de activos y el consumo de drogas ilícitas.

El mismo Instituto Kroc reconoce las dificultades por las que transita la paz territorial en Colombia, especialmente, porque «los puntos 4 y 1 están íntimamente relacionados dado que buscan transformar los contextos rurales de desigualdad que han permitido el surgimiento de las economías ilícitas» (2020: 65). Estas dificultades de avance en la implementación nuevamente se pueden observar en la matriz de seguimiento que propone esta entidad, cuyo último informe refleja el casi nulo avance de los programas de sustitución de cultivos ilícitos y mitigación de la producción y la comercialización de drogas, aún en fase incipiente.

Si se observa la evolución del cultivo cocalero en los últimos años y su relación con la geografía de la violencia, tal y como sucediera con el apartado anterior, resulta difícil encontrar una realidad que invite al optimismo a efectos de consolidar cualquier atisbo de paz territorial estable y duradera. Entre 2017 y 2019, la mayoría de los departamentos que presentan mayor concurrencia de estructuras criminales y, por extensión, mayor condensación de asesinatos a exguerrilleros de las FARC-EP y líderes sociales y mayores dificultades estructurales e institucionales para asumir la construcción de paz en clave territorial, son los mismos que arrastran los mayores niveles de cultivo cocalero. Antioquia, Caquetá, Cauca, Nariño, Norte de Santander y Putumayo llegan a representar más del 85,7\% de total de la producción cocalera de Colombia. Algo que, como apunta Nussio (2020), conecta a su vez con las mayores tasas de homicidio cada 100000 habitantes, pues mientras que en estos escenarios el promedio de muertes se eleva por encima de las 50, en el promedio nacional apenas se registran 23 muertes cada 100000 habitantes.

TABLA 8.

Producción cocalera de Colombia (en hectáreas Cultivadas, 20I7-2019)

\begin{tabular}{lccc}
\hline Departamento & $\mathbf{2 0 1 7}$ & $\mathbf{2 0 1 8}$ & $\mathbf{2 0 1 9}$ \\
\hline Antioquia & 13.680 & 13.403 & 9.481 \\
\hline Caquetá & 11.793 & 11.761 & 4.511 \\
\hline Cauca & 15.960 & 17.117 & 17.355 \\
\hline Narińo & 45.734 & 41.903 & 36.964 \\
\hline Norte de Santander & 28.244 & 33.597 & 41.710 \\
\hline Putumayo & 29.588 & 26.407 & 24.972 \\
\hline Resto del país & 21.495 & 24.830 & 19.482 \\
\hline Total Colombia & 171.494 & 169.018 & 154.475 \\
\hline
\end{tabular}

Fuente: elaboración propia a partir de los datos del Observatorio de Drogas. 


\section{CONCLUSIONES}

Pareciera evidente que la geografía de la violencia y las condiciones asociadas a ella, tras cuatro años desde la firma del Acuerdo de Paz con las FARC-EP, apenas ha cambiado. Las estructuras armadas y los diferentes grupos delincuenciales siguen teniendo un especial protagonismo en los escenarios de mayor producción de violencia, tal y como sucede con la región del Pacífico, el nororiente y el sur y suroccidente colombianos.

El componente territorial del Acuerdo ha atravesado por especiales dificultades, dada la persistencia de una acentuada brecha territorial, una acuciante debilidad institucional que se acompańa de una marcada violencia estructural, y por la concurrencia del negocio cocalero, que durante décadas ha servido de válvula de escape para entender la intensidad y la longevidad del conflicto armado. Además, la implementación del Acuerdo en lo que tiene que ver con el componente de construcción de paz territorial, concentrado en los puntos 1 y 4 del mismo, ha atravesado por importantes dificultades, siendo los menos desarrollados, con mucha diferencia, hasta el momento.

En el corto plazo comenzarán a publicarse aportaciones que, ya sea por herramientas estadísticas o desde metodologías discursivas, enriquecerán los análisis sobre expectativas, frustraciones, dificultades y transformaciones del Acuerdo de Paz. De este modo, este trabajo, con una pretensión más humilde, apenas intenta servir como un análisis exploratorio de cuál es la situación actual y del escaso nivel de transformación experimentado por la paz territorial hasta el momento.

Buena parte del escenario descrito en estas páginas sigue reivindicando que, más allá de su complejidad, la firma de un acuerdo de paz no es más que el comienzo de todo. Lo verdaderamente difícil reposa en la transformación de las estructuras socieconómicas, territoriales y simbólicas asociadas a la violencia. Mientras ello no suceda, lo esperable es que la violencia, lejos de remitir, se transforme y se adapte a nuevos entornos y dilemas. Es así como tras el abandono de las armas del grueso de las FARC-EP, tanto la violencia asociada al conflicto como la persistencia territorial de la misma han respondido a lógicas de continuidad y readaptación.

En cualquier caso, son también esperables los trabajos que pongan su acento en las experiencias exitosas, las lecciones aprendidas y las buenas prácticas que igualmente existen. Esto obliga a seguir reivindicando la necesidad de una correcta implementación del Acuerdo y la responsabilidad de la comunidad académica por explicar y visibilizar aquellos entornos locales en donde la realidad de la violencia ha sido superada por nuevos escenarios emergentes de construcción de paz en el plano local. Sea como fuere, parece evidente que el estudio de la violencia y su superación en Colombia mantienen intactas las ingentes posibilidades de análisis para la comprensión de un objeto de estudio que aún ofrece infinitas posibilidades interpretativas. 


\section{AGRADECIMIENTOS}

Este trabajo es resultado del proyecto posdoctoral del autor principal 2018-T2/ SOC-10508 y, asimismo, del proyecto PR65/19-22461, denominado "Discurso y expectativa sobre la paz territorial en Colombia: una mirada comparada entre las antiguas FARC-EP y las Fuerzas Militares». De este último, Jerónimo Ríos es investigador principal y ha sido financiado en la convocatoria de Proyectos de I+D para Jóvenes Doctores, resultado del marco del convenio plurianual entre la Administración de la Comunidad de Madrid y la Universidad Complutense de Madrid de 2019. Se agradece dicha financiación, así como el apoyo institucional de la Federación Colombiana de Municipios y la Organización de Estados Iberoamericanos

\section{Referencias}

Agnew, John. 1987. Place and Politics: The Geographical Mediation of State and Society. Londres: Allen and Uwin.

Aguilera, Mario. 2010. Las FARC: la guerrilla campesina 1949-2010. Bogotá: Arfo.

Ahumada, Consuelo. 2019. «La implementación del Acuerdo de paz en Colombia: entre la "paz territorial" y la disputa por el territorio", Problemas del Desarrollo, 50 (199): 25-47. Disponible en: https://doi.org/10.22201/iiec.20078951e.2020.200.69502.

Basedau, Matthias y Jan Pierskalla. 2013. «How Ethnicity Conditions the Effect of Oil and Gas on Civil Conflict: A Spatial Analysis of Africa from 1990 to 2010», Political Geography, 38 (1): 1-11. Disponible en: https://doi.org/10.1016/j. polgeo.2013.10.001.

Bejarano, Ana M. y Eduardo Pizarro. 2003. «Colombia: The Partial Collapse of the State and the Emergence of Aspiring State-Makers», en Paul Kingston y Ian Spears (eds.), States Within States: Incipient Politial Entitites in the Post-Cold War Era. Nueva York:Palgrave. Disponibleen: https://doi.org/10.1057/9781403981011_7.

Bracanti, Dawn. 2006. «Decentralization: Fueling the Fire or Dampening the Flames of Ethnic Conflict and Secessionism?», International Organization, 60 (3): 651-685. Disponible en: https://doi.org/10.1017/S002081830606019X.

Buhaug, Halvard y Jan Rød. 2006. «Local Determinants of Africa Civil Wars, 19702001», Political Geography, 25 (3): 315-335. Disponible en: https://doi. org/10.1016/j.polgeo.2006.02.005.

Cairo, Heriberto, Ulrich Oslender, Carlo Emilio Piazzini Suárez, Jerónimo Ríos, Sara Koopman, Vladimir Montoya Arango, Flavio Bladimir Rodríguez Muñoz y Liliana Zambrano Quintero. 2018. "Territorial Peace: The Emergence of a Concept in Colombia's Peace Negotiations», Geopolitics, 23 (2): 464-488. Disponible en: https://doi.org/10.1080/14650045.2018.1425110.

Cairo, Heriberto y Jerónimo Ríos. 2019. «Las elites políticas y la paz territorial en Colombia: un análisis del discurso en torno al Acuerdo de Paz», Revista Española de Ciencia Politica, 50: 91-113. Disponible en: https://doi.org/10.21308/recp.50.04. 
Cederman, Lars, Kristian Gleditsch e Idean Saleyhan. 2013. «Transborder Ethnic Kin and Civil War», International Organization, 67 (2): 389-410. Disponible en: https://doi.org/10.1017/S0020818313000064.

Centro Nacional de Memoria Histórica. 2013. ¡Basta Ya! Colombia: Memorias de guerra y dignidad. Bogotá.

Collier, Paul. 1994. "Demobilization and Insecurity: A Study in the Economics on the Transition from War to Peace», Journal of International Development, 6 (3):343-351. Disponible en: https://doi.org/10.1002/jid.3380060308.

Collier, Paul. 2009. "Post-conflict recovery: How should strategies be distinctive?», Journal of African Economies, 18 (1): 99-131. Disponible en: https://doi.org/10.1093/ jae/ejp006.

Comisión Económica para América Latina. 2019. Panorama Social de América Latina y el Caribe 2019. Santiago de Chile.

Consejería Presidencial para los Derechos Humanos y Asuntos Internacionales. 2020. Informe de homicidios contra lideres sociales y defensores de derechos humanos. Bogotá.

Departamento Nacional de Estadística. 2019. Colombia. Necesidades básicas insatisfechas 2018. Bogotá.

Echandía, Camilo. 2006. Dos décadas de escalamiento del conflicto armado en Colombia 1986-2006. Bogotá: Universidad Externado.

Echandía, Camilo e Irene Cabrera. 2017. Madurez para la paz. Bogotá: Universidad Externado.

Echandía, Camilo e Irene Cabrera. 2018. «La Fuerza Alternativa Revolucionaria del Común en las elecciones legislativas de 2018 (Catatumbo-Colombia)», FORUM. Revista Departamento Ciencia Politica, 16: 93-116. Disponible en: https://doi. org/10.15446/frdcp.n16.78174.

Estupiñán, Liliana. 2011. Desequilibrios territoriales. Bogotá: Universidad del Rosario.

Estupiñán, Liliana. 2018. «¿Es posible la paz territorial en Colombia? A propósito del Acuerdo Final de Paz entre Gobierno y Grupo FARC», Diritto Pubblico Comparado ed Europeo, 20 (2): 127-142.

Forø, Andreas y Halvard Buhaug. 2015. «Insurgency and Inaccessibility», International Studies Review, 17: 6-25. Disponible en: https://doi.org/10.1111/misr.12202.

Fundación Ideas para la Paz. 2019. La fragilidad de la transición. La paz incompleta y la continuación de la confrontación armada. Bogotá.

Fundación Ideas para la Paz. 2020. ¿Qué hacer con el ELN? Opciones ante una derrota militar lejana y un diálogo improbable. Bogotá.

Fundación Paz y Reconciliación. 2019. Más sombras que luces. La seguridad en Colombia a un año de Iván Duque. Bogotá.

Galtung, Johan. 1969. «Violence, Peace and Peace Research», Journal of Peace Research, 6 (3): 167-191. Disponible en: https://doi.org/10.1177/002234336900600301.

García de la Torre, Clara, y Clara Aramburo. 2011. Geografías de la guerra, el poder y la resistencia. Oriente y Urabá antioqueños, 1990-2008. Bogotá: CINEP. 
Hegre, Havard, Gudrun Ostby y Clionadh Raleigh. 2009. "Poverty and Civil War Events: A Disaggregated Study of Liberia", Journal of Conflict Resolution, 53 (4): 598-623. Disponible en: https://doi.org/10.1177/0022002709336459.

Henderson, James. 2010. Victima de la globalización. La historia de cómo el narcotráfico destruyó a Colombia. Bogotá: Siglo del Hombre.

Hendrix, Cullen. 2010. «Measuring State Capacity: Theoretical and Empirical Implications for the Study of Civil Conflict», Journal of Peace Research, 47 (3): 273-285. Disponible en: https://doi.org/10.1177/0022343310361838.

Hill, Richard, Gwendolyn Taylor y Jonathan Temin (2008). Would You Fight Again? Understanding Liberian Ex-Combatant Reintegration. Special Report, 211. Washington DC: USIP.

Horowitz, David. 1985. Ethnic Groups in Conflict. Berkeley: California University Press. Indepaz. 2018. Conflictos armados focalizados. Informe sobre grupos armados ilegales Colombia 2017-2018. Bogotá.

Indepaz. 2020. Paz al liderazgo social. Disponible en: http://www.indepaz.org.co/ paz-al-liderazgo-social/.

Instituto Kroc. 2017. Informe sobre el estado efectivo de implementación del Acuerdo de Paz en Colombia. Bogotá.

Instituto Kroc. 2020. Tres años después de la firma del Acuerdo Final de Colombia: hacia la transformación territorial. Bogotá.

Jaramillo, Sergio. 2014. La paz territorial. Presentación en la Universidad de Harvard, Cambridge, MA, Estados Unidos, 13-3-2014. Disponible en: http:// bit.ly/2YanTHV.

Junta de Inteligencia Conjunta. 2005. Estimación de los ingresos y egresos de las FARC durante 2003. Bogotá.

Le Billon, Philippe, María Roa y Angélica López. 2020. «Territorial peace and gold mining in Colombia: local peacebuilding, bottom-up development and the defence of territories», Conflict, Security, and Development, 20 (3): 303-333. Disponible en: https://doi.org/10.1080/14678802.2020.1741937.

Legrand, Catherine. 1988. Colonización y protesta campesina en Colombia. Bogotá: Centro. Lemaitre, Julieta y Esteban Restrepo. 2019. «Law and violence in the Colombian postconflict: state-making in the wake of the peace agreement", Revista de Estudios Sociales, 67: 2-16. Disponible en: http://dx.doi.org/10.7440/res67.2019.01.

Linke, Andrew y John O'Loughlin. 2015. «Reconceptualizing, Measuring, and Evaluating Distance and Context in the Study of Conflicts: Using Survey Data from the North Caucasus of Russia", International Studies Review, 17: 107-125. Disponible en: https://doi.org/10.1111/misr.12207.

Mashike, Lephophotho. 2007. Former Combatants Involvement in Crime and Crime Prevention. Research Report. Johannesburgh: Centre for the Study of Violence and Reconciliation.

McDoom, Omar. 2014. «Predicting Violence within Genocide: A Model of Elite Competition and Ethnic Segregation from Rwanda», Political Geography, 42 (1): 34-45. Disponible en: https://doi.org/10.1016/j.polgeo.2014.05.006. 
Mcfee, Erin y Angelika Rettberg. 2019. Excombatientes y acuerdo de paz con las FARC-EP en Colombia. Bogotá: Ediciones Uniandes. Disponible en: https://doi. org/10.30778/2019.39.

Medellín, Pedro y Alfredo Rangel. 2010. Política de Seguridad Democrática. Bogotá: Norma.

Ministerio de Defensa. 2019. Logros de la politica de defensa y seguridad. Bogotá.

Misión de Verificación de Naciones Unidas. 2020. Reporte del secretario general. Misión de Verificación de Naciones Unidas en Colombia. 26 de marzo de 2020.

Mouly, Cécile, Esperanza Hernández y Jaime Giménez. 2019. «Reintegración social de excombatientes en dos comunidades de paz en Colombia», Análisis Político, 32 (95): 3-22. Disponible en: http://dx.doi.org/10.15446/anpol.v32n95.80822.

Nussio, Enzo. 2018. «Ex-combatants and Violence in Colombia: Are Yesterday's Villains. Today's Principal Threat?», Third World Thematics: A TWQ Journal, 3: 135-152. Disponible en: https://doi.org/10.1080/23802014.2018.1396911.

Nussio, Enzo. 2020. "The Colombian Trap: Another Partial Peace», CSS Analyses in Security Policy, 258: 1-4.

O'Loughlin, John. 2012. "Climate Variability and Conflict Risk in East Africa, 19902009", Proceedings of the National Academy of Sciences of the United States of America, 45 (109): 18344-18349. Disponible en: https://doi.org/10.1073/pnas.1205130109.

Observatorio de Derechos Humanos y Derecho Internacional Humanitario (ODHDIH). (s. f.) Sintesis de la violencia y la confrontación armada en Colombia, 1998-2012 y 2015. Bogotá.

Observatorio de Drogas (s. f.). Disponible en: http://www.odc.gov.co/sidco/oferta/ cultivos-ilicitos/departamento-municipio.

Pattie, Charles y Ron Johnston. 2000. «People Who Talk Together Vote Together: An Exploration of Contextual Effects in Great Britain", Annals of the Association of American Geographers, 90 (1):41-66. Disponible en: https://doi.org/10.1111/00045608.00183.

Pécaut, Daniel. 2008. Las FARC, ¿una guerrilla sin fin o sin fines? Bogotá: Norma.

Pizarro, Eduardo. 2017. Cambiar el futuro: historia de los procesos de paz en Colombia (1981-2016). Bogotá: Debate.

Policía Nacional. 2019. «Seguridad ciudadana, violencia y criminalidad: una visión holística y criminológica de las cifras estadísticas del 2018», Revista Criminalidad, 61 (3): 9-58.

Programa de Naciones Unidas para el Desarrollo. 2011. Colombia rural. Razones para la esperanza. Bogotá.

Raleigh, Clionadh y Havard Hegre. 2009. «Population Size, Concentration and Civil War: A Geographically Disaggregated Analysis», Political Geography, 28 (4): 224-238. Disponible en: https://doi.org/10.1016/j.polgeo.2009.05.007.

Ramírez, Juan y Johan de Aguas. 2017. Escalafón de la competitividad de los departamentos de Colombia 2017. Bogotá: CEPAL.

Ramírez, William. 1990. Estado, violencia y democracia. Bogotá: Universidad Nacional de Colombia. 
Rettberg, Angelika et al. 2018. ¿Diferentes recursos, conflictos distintos? La economía politica regional del conflicto armado y la criminalidad en Colombia. Bogotá: Ediciones Uniandes. Disponible en: https://doi.org/10.30778/2018.09.

Rettberg, Angelika y Juan Ortiz. 2018. «Minería de oro, conflicto y criminalidad en los albores del siglo xxI en Colombia: perspectivas para el posconflicto colombiano", Colombia Internacional, 93: 17-63. Disponible en: http://dx.doi. org/10.7440/colombiaint93.2018.02.

Reyes, Alejandro y Ana M. Bejarano. 1988. "Conflictos agrarios y luchas armadas en la Colombia contemporánea: una visión geográfica», Análisis Político, 5: 6-27.

Ríos, Jerónimo. 2016. «La periferialización del conflicto armado colombiano, 20022014», Geopolitica(s). Revista de Estudios sobre Espacio y Poder, 7 (2): 251-275. Disponible en: https://doi.org/10.5209/GEOP.52270.

Ríos, Jerónimo. 2017. «Determinantes geográfico-políticos de la acción violenta guerrillera: un análisis de la concurrencia regional de guerrillas y paramilitares en el conflicto colombiano", Revista Española de Ciencia Política, 44, 121-149. Disponible en: https://doi.org/10.21308/recp.44.05.

Ríos, Jerónimo. 2021. Historia de la violencia en Colombia, 1946-2020. Una mirada territorial. Madrid: Sílex Ediciones.

Ríos, Jerónimo, Paula Bula y Jennifer Correa. 2019. "Departamentos de frontera y violencia periférica en Colombia», Revista Criminalidad, 61 (2): 113-132.

Ríos, Jerónimo, Julio González y William Pachón. 2020. «Risk assessment analysis of attacks on FARC ex-combatants: Towards a new evaluation model of probability», Journal of Policing, Intelligence, and Counter Terrorism, 15 (1): 44-63. https:// doi.org/10.1080/18335330.2020.1727945.

Rodríguez Iglesias, Ana. 2020. "Imagining peace(s) in Colombia. Between negotiations, policies, and resisting narratives», Araucaria. Revista Iberoamericana de Filosofia, Politica, y Humanidades, 22 (43): 99-117.

Salas, Luis. 2010. "Corredores y territorios del conflicto armado colombiano: una prioridad en la geopolítica de los actores armados», Perspectiva Geográfica, 15: 9-36.

Salas, Luis. 2016. "Conflicto armado y configuración territorial: elementos para la consolidación de la paz en Colombia», Bitácora, 26: 45-57. Disponible en: http:// dx.doi.org/10.15446/bitacora.v26n2.57605.

Saleyhan, Idean. 2009. Rebels Without Borders: State Boundaries, Transnational Opposition and Civil Conflict. Nueva York: Cornell University Press. Disponible en: https://doi.org/10.7591/9780801459214.

Sánchez, Gonzalo. 1987. Colombia: violencia y democracia: Comisión de Estudios para la Violencia. Bogotá: La Carreta.

Schutte, Sebastian. 2015. "Geography, Outcome and Casualties: A Unified Model of Insurgency», Journal of Conflict Resolution, 59 (6): 1101-1128. Disponible en: https://doi.org/10.1177/0022002713520534.

Schutte, Sebastian y Karsten Donnay. 2014. «Matched wake analysis: Finding causal relationships in spatiotemporal event data», Political Geography, 41 (1): 1-10. Disponible en: https://doi.org/10.1016/j.polgeo.2014.03.001. 
Snyder, Richard. 2006. «Does lootable wealth breed disorder?», Comparative Political Studies,39(8):943-968.Disponibleen:https://doi.org/10.1177/0010414006288724.

Taylor, Peter y Colin Flint. 2011. Political Geography: World-Economy, Nation-State and Locality. Londres: Routledge.

United Nations Office on Drugs and Crime (UNODC). 2020. Colombia. Monitoreo de cultivos de coca 2019. Viena: Naciones Unidas.

Villamizar, Darío. 2017. Las guerrillas en Colombia: una historia desde los orígenes hasta los confines. Bogotá: Debate.

Zukerman, Sarah. 2012. "Organizational legacies of violence: Conditions favoring insurgency onset in Colombia, 1964-1984», Journal of Peace Research, 49 (3): 473-491. Disponible en: https://doi.org/10.1177/0022343311435801.

Presentado para evaluación: 28 de julio de 2020.

Aceptado para publicación: 10 de enero de 2021.

\section{JERÓNIMO RÍOS}

jeronimo.rios@ucm.es

Investigador postdoctoral en la Facultad de Ciencias Políticas y Sociología de la Universidad Complutense de Madrid, como beneficiario de las Ayudas de Atracción del Talento Investigador que cofinancia la Comunidad de Madrid (2018).

JULIO C. GONZÁLEZ

julio.gonzalezr@unimilitar.edu.co

Profesor asociado de la Facultad de Relaciones Internacionales, Estrategia y Seguridad de la Universidad Militar Nueva Granada (Colombia). 